\title{
Humanized Care: A Challenge for Nursing
}

\section{Oscar Alberto Beltrán Salazar*}

Professor, School of Nursing, University of Antioquia, Colombia

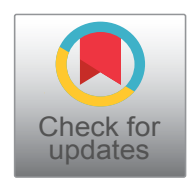

*Corresponding author: Oscar Alberto Beltrán Salazar, RN, Magister in Nursing, PhD in Nursing, Professor, School of Nursing, University of Antioquia, Medellin, Colombia, E-mail: oscar.beltran@udea.edu.co

The practice of health care currently reflects a constant tension between to be and should be, in other words, between what actually the care is and what it should be, up to limits in which people can speak of dehumanization [1]. This tension is evident in areas such as the relationship between the medical and nursing staff, the patients and their families, mediated by labor conditions, the use of technology and health administration often guided by reductionist criteria that have limited the interaction that underlies human care.

For some authors, the interest in current profit in the health system and health institutions has deeply penetrated into the staff providing care in a greater extent than their interest in respecting and defending the rights of people to the point that "militate in charge of the institutions in their interest to obtain better economic performance" [2] and turn to the side of the patients to facilitate the resolution of their problems, for this reason is not difficult to get refused the minimum necessary conditions for the effective care of health problems what goes against the nature of social practice oriented by ethical codes that governing the social exercise as the case of nursing.

Not surprisingly, it is found that patients want nurses to become humanitarian, friendly, available, receptive and willing to listen to them and likewise they are seeking to resolve the inconsistency between the view of nurses about their professionalism and what patients actually want from them and between theoretical approaches about nurse-patient interaction and what actually takes place with patients according to their age, health condition and culture [3]. This interaction is therapeutic in nature, aimed to meet the problems of patients [4] and nurses require adequate spiritual and emotional as well as intellectual development [5].
Nursing care is not limited only to satisfying the needs of physical nature or the implementation of prescriptions or the use of technological elements to measure and intervene physiological variables, but must be comprehensive, holistic and consider the charge of feelings such as frustration and uncertainty that patients may present due to illness sets them aside of everyday life, their context and cultural practices and leads them to be confined in a hospital ward, where everything is different and routine and where them could be subject to interventions, medications, procedures, tests and diets that can also cause anxiety and rejection.

Nursing care is personalized and has as the crucial strategy the nurse-patient interaction, in which the nurse is involved in the immediate context of the individual, while respecting their world, feelings, beliefs and meanings; it should also be focused on patients considering as ends and not as simple means for gain and profit under the premise that the starring role in care is assigned to the patient [6] and not the procedure, to the technique or those who hold the power on institutions and exert their dominance over nurses misrepresenting their work with the indiscriminate assignment of functions unrelated to the caring practice.

All these situations related to care, in summary, reflect the gap between the theoretical approaches that aim to orientate towards a humanized, responsible and high quality practice and actually, in which prevail personal and economic interests and the dominance of other professions which have led the care practiced by the nurses remarkable far from what is nursing care; also have shown that the context established in hospitals for patients with the participation of nurses and other professionals is not the expected context and yet

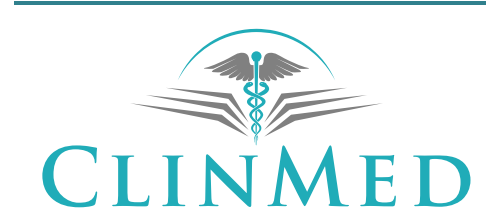

INTERNATIONAL LIBRARY

Citation: Salazar OAB (2018) Humanized Care: A Challenge for Nursing. Int Arch Nurs Health Care 4:092. doi.org/10.23937/2469-5823/1510092

Received: May 04, 2018: Accepted: May 08, 2018: Published: May 10, 2018

Copyright: (C) 2018 Salazar OAB. This is an open-access article distributed under the terms of the Creative Commons Attribution License, which permits unrestricted use, distribution, and reproduction in any medium, provided the original author and source are credited. 
has a strong importance on the meanings of the experiences of illness and care that patients developed.

In the resolution of this situation have a major participation nurse educators promoting research and the adoption of new knowledge, research consultants and evaluators promoting problem solving and knowledge creation and journal publishers disseminating and publicizing revisions and formulations of theories to allow the discipline advancement.

\section{References}

1. Brusco A (1998) Humanización de la asistencia al enfermo. Centro de Humanización de la Salud, Madrid.

2. Borrero YE (2008) Las reformas en el sector salud y los conflictos clasistas en Colombia: el caso de la ley 100/93.
Facultad de Ciencias Sociales y Económicas, Maestría en Sociología, Cali.

3. Hem MH, Heggan K (2003) Being professional and being human: One nurse's relationship with a psychiatric patient. J Adv Nurs 43: 101-108.

4. Vuokila-Oikkonen P, Janhonen S, Vaisanen L (2004) Shared rhythm cooperation in cooperative team meetings in acute psychiatric inpatient care. J Psychiatr Ment Health Nurs 11: 129-140.

5. Nouri JM, Ebadi A, Alhani F, Rejeh N, Ahmadizadeh MJ (2013) Qualitative study of humanization-based nursing education focused on role modeling by instructors. Nurs Health Sci 15: 137-143.

6. Henderson V (2000) Podemos dar un papel estelar a los pacientes. Investigación y Educación en Enfermería 18: 124-127. 